\title{
A new model for simulating growth in fish
}

A real dynamic population model calculates change in population sizes independent of time. The Beverton \& Holt $(\mathrm{B} \& \mathrm{H})$ model commonly used in fish assessment includes the von Bertalanffy growth function which has age or accumulated time as an independent variable. As a result the B\&H model has to assume constant fish growth. However, growth in fish is highly variable depending on food availability and environmental conditions. We propose a new growth model where the length increment of fish living under constant conditions and unlimited food supply, decreases linearly with increasing fish length until it reaches zero at a maximal fish length. The model is independent of time and includes a term which accounts for the environmental variation. In the present study, the model was validated in zebrafish held at constant conditions. There was a good fit of the model to data on observed growth in Norwegian spring spawning herring, capelin from the Barents Sea, North Sea herring and in farmed coastal cod. Growth data from Walleye Pollock from the Eastern Bering Sea and blue whiting from the Norwegian Sea also fitted reasonably well to the model, whereas data from cod from the North Sea showed a good fit to the model only above a length of $70 \mathrm{~cm}$. Cod from the Barents Sea did not grow according to the model. The last results can be explained by environmental factors and variable food availability in the time under study. The model implicates that the efficiency of energy conversion from food decreases as the individual animal approaches its maximal length and is postulated to represent a natural law of fish growth. 
1 Johannes Hamre, Institute of Marine Research, Bergen, Norway

2 Espen Johnsen, Institute of Marine Research, Bergen, Norway

3 Kristin Hamre, National Institute of Nutrition and Seafood Research (NIFES), Bergen, Norway

\section{Corresponding author:}

5 Kristin Hamre,

6 NIFES,

7 PO Box 2029,

85017 Bergen,

9 Norway

10 Phone: +4748185034

11 E-mail: $\underline{\text { kha@nifes.no }}$ 


\section{Introduction}

13 A main objective in fisheries management is to track the impact of fisheries on the fish stocks and

14 predict the Maximum Sustainable Yield (MSY) (Pitcher \& Hart 1982). A real dynamic

15 population model calculates changes in population size and biomass independent of time. In

16 mathematical terms, such a model is often formulated with differential equations where the

17 change is initially measured as a function of time. The time factor is then removed by integration,

18 but the differential models describing increment in biomass of fish cannot be integrated

19 (Beverton \& Holt 1957; Lotka 1925; Schaefer 1957; Volterra 1926). Furthermore, fish growth,

20 i.e. the size increment with time, varies greatly with food quality and availability, temperature

21 and other environmental factors and the fish will reach the different stages in development more

22 dependent on size than on age (Amara \& Lagardere 1995; Aritaki \& Seikai 2004; Sæle \& Pittman

23 2010). A certain size or energy store is needed for metamorphosis in fish larvae (Amara \&

24 Lagardere 1995; Aritaki \& Seikai 2004), smoltification in salmon (McCormick \& Bjørnsson

25 1994) and sexual maturation in fish in general. Accordingly, farmed cod grow faster and mature

26 at an earlier age than wild cod (Braaten 1984; Karlsen et al. 1995; Karlsen et al. 2006). If the

27 required size is not obtained, the fish will simply postpone development. Therefore, a growth

28 function which omits time and is based on fish size would be in line with real fish growth and

29 development, and would be preferred for calculation of yield in simulation models.

30 Population dynamic models built on the classical Beverton \& Holt (B\&H) model are often used

31 in fish stock assessments (Beverton \& Holt 1957; Hilborn 1994). This model estimates the yield

32 per recruit by assuming that growth is a function of age, e.g. accumulated time in line with

33 Bertalanffy (1938). As a result, the B\&H model cannot sum up the yield in all year classes in the

34 same year, but it can be used to sum up the yield in one year-class during life. The authors 
35 therefore assume that the yield of all year-classes in one year is equivalent to the yield of one

36 year-class through life (Beverton \& Holt 1957), e.g. the model assumes constant growth.

37 Another way to quantify changes in mass than using differential equations was introduced by

38 Albert Einstein, when he presented the theory of relativity. Instead of using mathematics to

39 deduce from a known physical law, he postulated that energy and mass are equivalents and

40 depend on the speed of light (Einstein 1905). Einstein's postulate was effectively proven by the

41 testing of the nuclear bombs and by later experiments with particle acceleration. Our postulate is

42 that the length increment $(\mathrm{dL})$ is inversely proportional to the length (Ls) and that dL is reduced

43 towards a maximum length (Lmax):

$$
\mathrm{dL}=\mathrm{k} \cdot(\operatorname{Lmax}-\mathrm{Ls})
$$

$46 k$ is a variable determined by environmental factors, such as food availability and temperature.

47 Eq. 1 includes only measurable factors so that dL can be summed arithmetically, either per year

48 or by year classes, using computer techniques. It can be applied for vertebrates, only, because the

49 dynamic term (Lmax-Ls) cannot be negative, i.e. the animal cannot shrink.

50 The present study aims at developing a real dynamic growth model of fish biomass based on an

51 unchangeable and predictable natural law which is independent of time. Since environmental

52 conditions modulate growth, we used an experiment with zebrafish (Danio reirio) kept at

53 constant conditions and fed Artemia for one generation (Gomez-Requeni et al. 2010) to validate

54 the growth model. Another experiment, where zebrafish were fed a formulated diet from first-

55 feeding until sexual maturation, also under near constant environmental conditions (Kaushik et

56 al., 2011), is included. We also investigate how the model fits to the observed growth of 
57 Norwegian spring spawning herring (Clupea harengus), herring and blue whiting

58 (Micromesistius poutassou) in the Norwegian Sea, North East Atlantic capelin (Mallotus villosus)

59 and cod (Gadus morhua), cod from the North Sea, farmed cod originating from a Norwegian

60 costal stock and Walleye Pollock (Theragra chalcogramma) from the North Pacific. Later we

61 intend to use this law to simulate the development in fish stocks, starting with measurement of

62 the state of the stocks using acoustic surveys, in accordance with Bjerknes' principle of exact

63 science (Bjerknes 1904)

\section{Materials and methods}

65 Data acquisition and organisation

66 The data on growth in zebrafish were extracted from Gomez-Requeni et al. (2010) and Kaushik

67 et al. (2011). Briefly, in the first experiment, the zebrafish were held in 50 5L tanks at 8 fish per

68 tank from 16 until $103 \mathrm{dpf}$ (days post fertilization) and fed Artemia nauplii as the only diet from

6916 dpf. Before 16 dpf, a dry commercial diet was fed. Photoperiod was 13L:11D (light:dark), and

70 water temperature was constantly kept at $28^{\circ} \mathrm{C}$. Mean values for $\mathrm{pH}$ and conductivity were 7.21

71 and $685 \mu \mathrm{S}$, respectively. At regular intervals, approximately 30 fish were sacrificed and fork

72 length and body weight were measured. In the second zebrafish experiment, the fish were held in

$7310 \mathrm{~L}$ aquaria which were connected to a water recirculation system. The fish density was initially

74350 fish per tank and reduced to 150 fish per tank when the fish reached $15 \mathrm{~mm}$ total length (TL).

75 Two days after hatching, triplicate groups of fish started receiving a dry micro-particulate feed of

76 commercial origin (Gemma micro; Skretting). Feed was distributed by hand to fish four times

77 daily to visual satiety until circa $12 \mathrm{~mm}$ TL and two to three times daily thereafter. The pellet size

78 was increased as the fish grew. Temperature was maintained at $28^{\circ} \mathrm{C}$, $\mathrm{pH}$ at $7.0-7.5$, oxygen 
79 saturation at 70\%-95\%, and photoperiod at 14L:10D (light:dark). 8-10 fish were taken for

80 measurement of TL at regular intervals.

81 Mean lengths (L) of Norwegian spring spawning herring, and North Atlantic capelin and cod

82 were from ICES working group reports (ICES 2012a; ICES 2012c). In herring, data on 1 to 9

83 year old fish, from 1985 until 2003 were used, while fish older than 9 years were omitted from

84 the dataset, because they had essentially no length increment. The data were organized as

85 development of length with age in different year classes. Full year classes were obtained from

86 those reaching one year of age in 1985-1995. The North Sea herring data are given as the mean

87 length at age measured during the acoustic surveys in June-July 2002-2012, and collected from

88 the ICES herring assessment working groups for the area south of $62^{\circ} \mathrm{N}$ (ICES 2013). Data on

89 capelin and cod from the Barents Sea were also organized as development of length per year-

90 class, the 1986-2001 year-classes for capelin and the 1985-1995 year-classes for cod. Data on

91 weights of North Sea cod were taken from the ICES working group report ICES (2012b) and

92 converted to length using a condition factor of 0.0104 (Daan 1974). The data on farmed cod were

93 from Norwegian coastal cod hatched at Parisvannet and reared in 5x5x5 m3 pens at Austevoll

94 Aquaculture Research Station, Institute of Marine Research, Bergen Area, Norway. All fish were

95 fed in moderate excess with commercial dry pellets (Tess Marine, Skretting AS, Stavanger,

96 Norway; $49 \%$ protein, $7.1 \%$ lipid and 33.5\% carbohydrate). The temperature measured at $2 \mathrm{~m}$

97 depth varied between approximately $14^{\circ} \mathrm{C}$ in July-September to $5^{\circ} \mathrm{C}$ in February-April and the

98 salinity varied between 28 and $32 \mathrm{~g} \mathrm{~L}-1$. The fish became sexually mature at an age of 2 years

99 (Lehman et al., 1990; Kjesbu and Holm 1994). Pollock data, which are collected during bottom

100 trawl surveys, were kindly communicated by Stan Kotwicki at the Alaska Fisheries Science

101 Center, National Marine Fisheries Service. The Pollock stock is described in Ianelli et al. (2011). 
102 Blue whiting data are collected from Norwegian landings west of the British Isles where the main

103 fishery takes place in February-April. The data were kindly provided by Kjell Utne Rong,

104 Institute of Marine Research, Norway. . Both Pollock and blue whiting data were organized as

105 development of length per year class, for the 1982-2000 and 1982-2004 year classes,

106 respectively.

107 Calculations and statistics

108 Increment in length (dL) was calculated as $\mathrm{dL}=\mathrm{L}_{(\mathrm{a}+1)}-\mathrm{L}_{(\mathrm{a})}$, where a is fish age, using time intervals

109 of one day for zebrafish, one year for farmed cod and for the wild fish stocks.

110 The statistical treatment was performed with GraphPad Prism, ver. 6 for Windows (GraphPad

111 Inc., La Jolla, CA, USA). For the zebrafish data of Gomez-Requeni et al. (2010), the plot of

112 length increment day ${ }^{-1}$ by length was first fitted to a second order polynomial equation. The

113 points after the maximum of the obtained parable were then fitted to a linear and a second order

114 polynomial equation and the results compared using the GraphPad software. The zebrafish data

115 of Kaushik et al., (2011) of length increment by length were fitted to a linear equation. For

116 herring, capelin, wild and farmed cod, average length increment year ${ }^{-1}$ by length in the year-

117 classes were also fitted to a linear and a second order polynomial equation, and the results

118 compared by the software.

119 For Norwegian spring spawning herring, length increment year ${ }^{-1}$ for 1-9 year old fish could be

120 fitted to a linear equation in some of the year classes, while in other year classes, one and two

121 year old fish had lowered length increment. In all cases, $\mathrm{R}^{2}>0.98$ for 3-9 year old fish and Lmax

122 could be calculated from these data (average Lmax=354 $\mathrm{mm}$ ), while the slope of the line equals $\mathrm{k}$

123 in this period. $\mathrm{k}$ in one and two year old fish, when they deviated from the linear relationship, was 
124 calculated as the slope of the straight line between length increment year ${ }^{-1}$ in these fish and

125 Lmax.

\section{Results}

127 In the experiment of Gomez-Requeni et al. (2010), zebrafish growth as a function of age fits a

128 sigmoid curve (Figure 1A), and plotting length increment as a function of length gave an almost

129 perfect fit to the second order polynomial $y=-0.0027 x^{2}+0.078 x+0.25\left(R^{2}=0.994\right.$, Figure 1B).

130 When omitting the first two points corresponding to the larval and very early juvenile stages, and

131 comparing the polynomial $\left(\mathrm{R}^{2}=0.9988\right)$ and the linear equation, the second order polynomial was

132 preferred $(\mathrm{p}=0.015)$, but the straight line still had an $\mathrm{R}^{2}=0.9887$ (Figure $\left.1 \mathrm{C}\right)$. Therefore, growth in

133 zebrafish held at constant conditions after the juvenile stage can be formulated mathematically by

134 equation 1 :

$135 \mathrm{dL}=\mathrm{k} \cdot(\mathrm{Lmax}-\mathrm{Ls})=-\mathrm{k} \cdot \mathrm{Ls}+\mathrm{k} \cdot \mathrm{Lmax}$

136 The slope of the curve corresponds to $-\mathrm{k}$, while Lmax can be calculated from the intercept with

137 the y-axis; $\mathrm{k}^{\cdot} \operatorname{Lmax}$ (Figure 1C).

138 The experiment of Kaushik et al. (2011), with zebrafish, showed a less regular growth curve as

139 length by age (Figure $1 \mathrm{~A}$ ). Fitting Eq. 1 to the data still gave an $\mathrm{R}^{2}=0.55$, the fit to the $2^{\text {nd }}$ order

140 polynomial equation han an $\mathrm{R}^{2}$ of 0.60 , but was rejected $(\mathrm{p}=0.58)$. The slopes of the lines were

141 not different, but the difference in Lmax between the two zebrafish groups was highly significant $142(p=0.0007$, Figure 1C). 
143 The curve of length by age of the 1985 to the 1995 year-classes of herring from 1 until 9 years of

144 age (Fig 2A) shows rapid growth in length of young fish and a decrease in length increment as

145 the fish get older and increase in size. The decrease in length increment starts already after the

146 second year and lasts until year 9, where-after the length increment per year is close to zero (data

147 not shown). Figure 2B shows the plot of average length increment by length in all year-classes.

148 The fit to a second order polynomial has an $\mathrm{R}^{2}=0.9979$, while the linear fit has an $\mathrm{R}^{2}=0.9904$.

149 Here the second order equation is again preferred $(p=0.01)$. Figure $2 \mathrm{C}$ and $2 \mathrm{D}$ shows that the 150 plots of length increment by length differ in the different year classes. In 1988 and -89, length

151 increment through the whole life cycle fitted a linear equation (Figure 2C), while in 1993, length 152 increment in one and two year old fish was low compared to that in 1988 and 89 and deviated 153 from the linear equation obtained for 3-9 tear old fish. The length increment for 1 and 2 year old 154 fish deviated from the straight line obtained for in 3-9 year old fish $\left(\mathrm{R}^{2}>0.98\right)$ in the year-classes $1551985,-86,-92,-93$ and -94 . The length increment in 1 year old fish deviated from the straight line 156 obtained for 2-9 year old fish $\left(\mathrm{R}^{2}=0.99\right)$ in the year-class 1987 . All ages fitted a straight line in the 157 1988, $-89,-90,-91$ and -95 year-classes $\left(\mathrm{R}^{2}>0.98\right)$. Assuming that the deviations from the linear 158 relationship are due to differences in environmental conditions that can be expressed by $\mathrm{k}$, $\mathrm{k}$ was 159 plotted by year-class for 1 year old, 2 year old and 3-9 year old herring, respectively, from 1985 160 to 1995 (Figure 3).

161 Growth in capelin given as length by age is shown in Figure 4A. As in herring, the length

162 increment decreases as the fish increase in size, however the number of points in the regression is 163 limited by the life span of capelin, which is only 4-5 years, since almost all fish die after the first 164 spawning. Average length increment by length in the year-classes from 1986 to 2001 is given in 165 figure $4 \mathrm{~B}$ with a $2^{\text {nd }}$ order polynomial fit $\left(\mathrm{R}^{2}=0.9983\right)$ and a linear fit $\left(\mathrm{R}^{2}=0.9766\right)$. In this case, 166 the linear equation was preferred $(p=0.17)$. 
167 Figure 5 shows the age and length dependent growth of North Sea herring, blue whiting from the 168 Norwegian Sea and Walleye Pollock from the Eastern Bering Sea. In North Sea herring (Figure $1695 \mathrm{~A}$ and $5 \mathrm{~B})$, Eq. 1 and the $2^{\text {nd }}$ order polynomial model did not give different $\mathrm{R}^{2}(0.97$ and 0.98 , 170 respectively, $\mathrm{p}=0.36$ ). In blue whiting (Figure $5 \mathrm{~B}$ and $5 \mathrm{C}$ ), the $\mathrm{R}^{2}$ were 0.89 and 0.98 for the

171 linear versus the polynomial model and the polynomial model was preferred $(\mathrm{p}=0.02)$. A similar 172 situation was found in Pollock (Figure 5D and 5E) where $\mathrm{R}^{2}$ were 0.95 and 0.99 , respectively, 173 and again a polynomial model was preferred $(\mathrm{p}=0.0002)$. For both blue whiting and Pollock, the

174 constant of the first order term of the polynomial model was negative, inverting the curve

175 compared to the polynomial models fitted to growth data of the other species.

177 Growth in Northeast Arctic cod of different year-classes, given as length by age, seems to fit a 178 linear equation, not a sigmoid curve as in the other fish stocks (Figure 6A). Average length 179 increment by length did not decrease with size to the same extent as in the other fish species, 180 varying between 11 and $8 \mathrm{~cm}$ year $^{-1}$ (Figure 6B). Regression analyses using data from individual 181 year classes gave variable and sometimes poor relationships, with $\mathrm{R}^{2}=0.85-0.27$ for the second 182 order and $\mathrm{R}^{2}=0.88-0.06$ for the linear relationship. Growth in North Sea cod given as length by 183 age (Figure 6C), did follow a sigmoid curve. Length increment by length (Figure 6D) showed a 184 good fit after the fish had reached a length of $70 \mathrm{~cm}$ to Eq. $1\left(\mathrm{R}^{2}=0.98\right)$. The $2^{\text {nd }}$ order polynomial 185 fit for this period was rejected $\left(\mathrm{R}^{2}=0.98, \mathrm{p}=1.0\right)$. Before the fish reached $70 \mathrm{~cm}$, length increment 186 was lowered compared to what is predicted by Eq. 1. Growth in length by age in farmed cod kept 187 at relatively constant conditions and fed a dry diet to satiation, followed an asymptotic curve, 188 length increment by length in showed a good fit to Eq. 1 (Figure $6 \mathrm{E}, \mathrm{R}^{2}=0.85$ ) and the linear 189 function was preferred over the second order one $(\mathrm{p}=0.32)$. 


\section{Discussion}

191 The questions asked in this study are: 1) Do fish grow according to an unchangeable natural law,

192 independent of time? 2) Can such a law be described by Eq. 1? The first question cannot be

193 proved using mathematical deduction, but we postulate a law in a similar way as Albert Einstein

194 postulated the theory of relativity. Question 2 is validated by referring to a model organism for

195 mechanistic biological research, zebrafish.

196 The zebrafish from which the present growth curves were extracted had been held at constant

197 environmental conditions and fed Artemia, only, from $16 \mathrm{dpf}$, or a formulated diet from 5 dpf,

198 according to standard feeding regimes, until the fish were past sexual maturation (Gomez-

199 Requeni et al., 2010; Kaushik et al., 2011). The first experiment created a conventional sigmoid

200 curve of weight by age, which seems to be common in all terrestrial vertebrates (Dumas et al.

201 2010). According to Dumas et al. (2010) and references therein, there is doubt that fish approach

202 a maximum weight, since growth continues after sexual maturation. In our opinion, the data

203 presented here strongly indicate that an Lmax exists for a number of fish species and that varying

204 environmental conditions can explain why an Lmax appears less evident in some of the species.

205 In order to omit time from the growth equation, length increment was plotted as a function of

206 length. Regarding the data on zebrafish growth from Gomez-Requeni et al. (2010), this plot had

207 an almost perfect fit to a second order equation, e.g. length increment increased in larval and

208 early juvenile fish (9-30 dpf), approaching a maximum, and decreased gradually in larger fish,

209 reaching zero at a maximal length (Lmax). In the experiment of Kaushik et al. (2011) length

210 increment in 13-20 dpf fish, was higher than length increment in older fish. This may indicate

211 that the lower growth in young fish in the first experiment had to do with a concomitant shift 
212 from a dry diet to Artemia at $16 \mathrm{dpf}$. Artemia are too big to be eaten by first-feeding larvae, and it

213 may be that the fish still needed some time after the diet shift before it could utilize Artemia at

214 maximal efficiency. In the second experiment the fish had been fed the same formulated diet from

215 first-feeding at $5 \mathrm{dpf}$ until the end of the experiment, only pellet size being adjusted to the fish

216 size. The high growth of the early larvae in this experiment, where there was no change of feed,

217 indicates that Eq. 1 is also valid also for young zebrafish. The large variation in length increment

218 relative to the regression line may be explained by the lower number of fish measured per point

219 and/or the difficulty in feeding a formulated diets to small fish. Length increment leads to

220 accumulation of biomass and energy. Therefore, the model implies that energy in the food is used

221 most efficiently for biomass accumulation in relatively small fish, with decreasing efficiency as

222 the fish approach Lmax. The linear model given in Eq. 1 can also be seen as a simple version of

223 the second half of the $2^{\text {nd }}$ order growth function. It fits well to the data for zebrafish past

224 maximum length increment in the first experiment, even though it is not statistically preferred

225 over the $2^{\text {nd }}$ order equation. Eq. 1 is easy to understand, it can readily be adapted in simulation

226 models and it includes the variable k, which describes changes in the environment and food

227 availability. Furthermore, the assessment of fish stocks most often only includes fish that are

228 larger than the point where maximal length increment occurs in the experiment of Gomez-

229 Requeni et al. (2010), again favoring the use of Eq. 1.

230 Eq. 1 also fits the length increment by length data for the year-classes of fish, one year old or

231 more, of North Sea herring, capelin and farmed cod. The data from Norwegian Spring Spawning

232 herring of 3-9 years are very well described by Eq. 1, but in some of the year-classes, one and

233 two year old fish grow slower than the prediction of Eq. 1. The deviation from the straight line is

234 present in some year-classes, but not in others. Therefore we have interpreted it as a difference in

235 environmental conditions, e.g. a difference in $\mathrm{k}$. The cause of a lowered $\mathrm{k}$ in young herring may 
236 be that they grow up in the colder Barents Sea and move to the Norwegian Sea when they are 20-

$23722 \mathrm{~cm}$, usually about three years old (Holst et al. 2004).

238 Length increment by length in cod from the Barents Sea shows a variable and generally poor fit

239 to Eq. 1. This may be caused by low and varying food availability, since the Northeast Arctic cod

240 stock is large and may therefore encounter food shortage (Jørgensen 1992). The stock also

241 encounters temperatures that are near it`s minimum tolerance level, which would have a large

242 effect on growth (Dumas et al., 2010). Furthermore, older and larger Northeast Arctic cod have a

243 tendency to distribute further to the west, where they encounter gradually increasing temperatures

244 (Michalsen et al. 1998). The slow reduction of length increment when length increases in

245 Northeast Arctic cod, may therefore be explained by a temperature dependent increase in $\mathrm{k}$ from

246 one year to the next over the whole life span. Unfortunately, the data from Northeast Arctic cod

247 cannot be used to determine Lmax, so that $\mathrm{k}$ cannot be defined per year.

248 The farmed cod were held under semi-controlled conditions, in net pens with ambient sea-water

249 temperature and natural light, but were fed the same diet using the same feeding regime for one

250 generation. The measurements were taken in summer and winter and the relatively large variation

251 is related to the seasonal variation in temperature and light. When only winter measurements

252 were included, e.g. the length increment from one winter to the next was monitored, there was a

253 perfect fit of the data to Eq. $1\left(\mathrm{R}^{2}=1.00\right)$. Eq. 1 also fits well to data from North Sea cod larger

254 than $70 \mathrm{~cm}$ and is preferred over the $2^{\text {nd }}$ order polynomial fit. However, North Sea cod with a

255 length below $70 \mathrm{~cm}$ do not grow according to the prediction of Eq. 1. Since the farmed cod which

256 was held at fairly constant conditions did grow according to Eq. 1, and that cod older than 0.5

257 years therefore seems to grow according to this relationship, it can be speculated that small North 
258 Sea cod encounter environmental conditions and food availability that are inferior to that of the 259 larger cod.

260 In blue whiting and Pollock the best fit of the growth data was obtained with a second order

261 polynomial model which was inverted compared to that in zebrafish (Figure 1B). This could be 262 interpreted as an indication that these species do not have an Lmax. However, it could also be an 263 effect of varying environmental conditions in different life stages, where very young fish and 264 spawning fish have more favorable conditions than juvenile fish. It was reported by Ianelli et al. 265 (2011) that different size Walleye Pollock were found in different areas. Furthermore, data from 266 both species had a relatively good fit to Eq. 1 , with $\mathrm{R}^{2}=0.89$ and 0.95 , respectively.

267 In Eq. 1, Lmax and $\mathrm{k}$ are individual characteristics determined by how the fish have adapted to 268 the environmental conditions. Lmax is different from L $\infty$ in von Bertalanffy's growth function 269 (Bertalanffy 1938); it is a fixed value, not an asymptote, it has a variance and it is not connected 270 to time. Lmax is assumed to be genetically determined, and may change in response to long term 271 changes in the environment and harvesting strategies, as described for North West Arctic cod by 272 Borrell (2013). It differs between species, between the stocks within a species and between the 273 individuals within a stock. The different Lmax values for the two zebrafish strains discussed in 274 this study (Gomez-Requeni et al., 2010; Kaushik et al., 2011) is an example of this variability. 275 Clearly, there is a considerable number of variables that determine the value of $\mathrm{k}$, and the 276 parameterization will demand expertise within oceanography and in biological fields such as 277 genetics and nutrition.

278 Eq. 1 calculates length increment, while yield in biomass is the economically important variable. 279 It has been shown that specific growth rate (SGR) in \% of body weight per day has a linear 
relationship to fish weight on a log-log scale (Bjørnsson \& Steinarsson 2002; Braaten 1984; Brett

281 \& Shelbourn 1975; Iwama \& Tautz 1981; Jobling 1983), which is an alternative formulation of

282 the natural law of animal growth to Eq. 1. One reason for using length in our model is that both

283 length of individual fish and number of fish can be measured directly using acoustic trawl

284 surveys. The length increment data can then be converted to yield in weight and biomass using

285 Fulton's condition factor (Fulton 1904). In aquaculture, Eq. 1 can be used to compare growth of

286 individual fish and calculate yield of a standing stock of fish, both of which are related to k, and

287 Lmax in different populations of fish can be determined.

288 According to Eq. 1, harvesting of fish which are at the point of maximum size increment is 289 energetically most efficient. In the case of herring, fish of $10 \mathrm{~cm}$ length grow at a rate which is

290 four times higher than fish of $30 \mathrm{~cm}$ length (Figure 2B). Feed conversion efficiency generally 291 increases with higher growth rates in fish (Kolstad et al. 2004), so utilization of the energy from 292 plankton would be optimized by harvesting relatively small fish. The slaughter of farm animals 293 prior to sexual maturation is a common practice in meat and fish farming which also takes 294 advantage of the high growth rates in young animals. Selective fisheries on large fish may 295 therefore defeat its own end, and prevent a maximum utilization of the marine resources. A 296 similar perspective is presented by Borrell (2013), however the discussion of harvesting strategies 297 has many aspects that need consideration beyond the scope of this study. Ecological principles 298 may also be explained as optimizing the efficiency of energy utilization. An example is the 299 seabirds along the Norwegian coast, which mainly feed on 0-group fish (Dragesund et al. 2008), 300 taking out fish that are in the phase of maximum energy conversion. This represents an efficient 301 utilization of zooplankton biomass and energy.

\section{Conclusion}


303 The data presented here indicate that there is a natural law for length increment in fish, based on

304 achieved length, which can be described by Eq. 1. Generally, data from young fish often deviate

305 from the straight line obtained by fitting data from older fish to the model. This may be caused by

306 varying environment conditions in different life stages of the wild fish. A consequence of Eq. 1 is

307 that the efficiency of energy conversion from food decreases as the individual animal approaches

308 Lmax. Length increment represents yield in biomass and energy and is the way living organisms

309 store energy from the sun. Eq. 1 enables us to quantify these processes.

\section{Acknowledgements}

311 We want to thank P. Gomez-Requeni P and I. Rønnestad, the University of Bergen, Norway, for

312 providing one of the datasets on Zebrafish and Ø. Karlsen, The Institute of Marine Research,

313 Bergen, Norway, for the dataset on farmed cod Thanks to Kjell Utne Rogn, The Institute of

314 Marine Research for the blue whiting data, to Stan Kotwicki, the Alaska Fisheries Science

315 Center, for data on Walleye Pollock, and Cecilie Kvamme, the Institute of Marine Research for

316 tabulating the data on North Sea herring. Samuel J. Penglase is acknowledged for critical reading

317 of the manuscript. 
319 Amara R, and Lagardere F. 1995. Size and age at onset of metamorphosis in sole (Solea-Solea 320 (L)) of the Gulf of Gascogne. Ices Journal of Marine Science 52:247-256.

321 Aritaki M, and Seikai T. 2004. Temperature effects on early development and occurrence of 322 metamorphosis-related morphological abnormalities in hatchery-reared brown sole 323 Pseudopleuronectes herzensteini. Aquaculture 240:517-530.

324 Bertalanffy L.von 1938. A quantitative theory of organic growth. Human Biology 10:181-213.

325 Beverton RJH, and Holt SJ. 1957. On the dynamics of exploited fish populations. Fisheries 326 Investigation, London, Series 2 19:1-533.

327 Bjerknes V. 1904. Das problem der Wetterforhersage, betractet vom Standpunkte der Mekanik 328 und der Physik. Meterologische Zeitschrift, Wien 21:1-7.

329 Bjørnsson B, and Steinarsson A. 2002. The food-unlimited growth rate of Atlantic cod (Gadus 330 morhua). Canadian Journal of Fisheries and Aquatic Sciences 59:494-502.

331 Borrell B. 2013. A big fight over little fish. Nature 493:597-598.

332 Braaten B. 1984. Growth of cod in relation to fish size and ration level. In: Dahl E, Danielssen 333 DS, Moksness E, and Solemdal P, eds. The propagation of cod (Gadus morhua L). Arendal, Norway: Institute of Marine Research, 677-710.

335 Brett JR, and Shelbourn JE. 1975. Growth-Rate of Young Sockeye Salmon, Oncorhynchus336 337 Nerka, in Relation to Fish Size and Ration Level. Journal of the Fisheries Research Board of Canada 32:2103-2110.

338 Cook RM, Sinclair A, and Stefansson G. 1997. Potential collapse of North Sea cod stocks. $339 \quad$ Nature 385:521-522.

340 Daan N. 1974. Growth of North Sea cod, Gadus morhua. Netherlands Journal of Sea Research 341 8:27-48. 
342 Dragesund O, Østvedt OJ, and Toresen R. 2008. Norwegian spring spawning herring: History of

343 fisheries, biology and stock assessment. In: Nakken O, ed. Norwegian Spring Spawning 344 Herring and North East Atlantic Cod. Trondheim, Norway: Tapir Academic Press, 41-82.

345 Dumas A, France J, and Bureau D. 2010. Modelling growth and body composition in fish 346 nutrition: where have we been and where are we going? Aquaculture Research 41:161$347 \quad 181$.

348 Einstein A. 1905. Zur Electrodynamik bewegter Körper. Randiconti del Circolo Matematico di 349 Palermo.

350 Fulton TW. 1904. The rate of growth in fishes. Fish Board Scotland, Ann Rep 22:141-241.

351 Gomez-Requeni P, Conceicao LEC, Jordal AEO, and Ronnestad I. 2010. A reference growth 352 curve for nutritional experiments in zebrafish (Danio rerio) and changes in whole body proteome during development. Fish Physiology and Biochemistry 36:1199-1215.

Hilborn R. 1994. Book reveiw: Beverton, R.J.H. \& Holt, S.H. On the Dynamics of Exploited Fish Populations. Reviews in Fish Biology and Fisheries 4: 259-266.

Hoie H, Andersson C, Folkvord A, and Karlsen O. 2004. Precision and accuracy of stable isotope signals in otoliths of pen-reared cod (Gadus morhua) when sampled with a highresolution micromill. Marine Biology 144:1039-1049.

Holst JC, Røttingen I, and Melle W. 2004. The herring. In: Skjoldal H-R, Sætre R, Faernö A, Misund OA, and Røttingen I, eds. The Norwegian Sea ecosystem. Trondheim: Tapir Academic Press, 203-226.

Ianelli, J.N., Honkalehto, T., Barbeaux, S., Kotwicki, S., Aydin, K. and Williamson, N., 2011. Assessment of the walleye pollock stock in the Eastern Bering Sea. Alaska Fisheries 
366

367

368

369

370

371

372

373

374

375

376

377

378

379

380

381

382

383

384

385

386

387

388

389

390

ICES. 2012a. Report of the Arctic Fisheries Working Group 2012 (AFWG), 20 - 26 April 2012. Copenhagen: ICES Headquarters.

ICES. 2012b. Report of the Working Group on the Assessment of Demersal Stocks in the North Sea and Skagerrak (WGNSSK), 27 April - 3 May 2012. Copenhagen: ICES Headquarters, Copenhagen

ICES. 2012c. Report of the Working Group on Widely Distributed Stocks (WGWIDE), 21 - 27 August 2012. Lowestoft, United Kingdom.

ICES 2013. Report of the Herring Assessment Working Group for the Area South of $62 \mathrm{~N}$ (HAWG). 12-21 March 2013, ICES Headquarters, Copenhagen.

Iwama, G.K. and Tautz, A.F., 1981. A simple growth model for salmon in hatcheries. Canadian Journal of Fisheries and Aquatic Sciences, 38:649-656.

Jobling M. 1983. Growth-studies with fish - Overcoming the problems of size variation. Journal of Fish Biology 22:153-157.

Jørgensen T. 1992. Long-term changes in growth of North-east Arctic cod (Gadus morhua) and some environmental influences. ICES Journal of Marine Science: Journal du Conseil 49:263-278.

Karlsen O, Holm JC, and Kjesbu OS. 1995. Effects of Periodic Starvation on Reproductive Investment in 1st-Time Spawning Atlantic Cod (Gadus-Morhua L). Aquaculture 133:159170.

Karlsen O, Norberg B, Kjesbu OS, and Taranger GL. 2006. Effects of photoperiod and exercise on growth, liver size, and age at puberty in farmed Atlantic cod (Gadus morhua L.). Ices Journal of Marine Science 63:355-364.

Kaushik, S., Georga, I., Koumoundouros, G., 2011. Growth and Body Composition of Zebrafish (Danio rerio) Larvae Fed a Compound Feed from First Feeding Onward: Toward Implications on Nutrient Requirements. Zebrafish, 8:87-95. 
391 Kjesbu OS, and Holm JC. 1994. Oocyte reqruitment in first-time spawning Atlantic cod (Gadus morhua) in relation to feeding regime. Can J Fish Aquat Sci 51:1893-1898.

393 Kolstad K, Grisdale-Helland B, and Gjerde B. 2004. Family differences in feed efficiency in 394 Atlantic salmon (Salmo salar). Aquaculture 241:169-177.

395

Lehmann GB, Karlsen Ø, Holm JC, and Riple BE. 1990. Vekst og kjønnsmodning hos 396 oppdrettstorsk. L.nr. Akva19/90. Institute of Marine Research, Bergen, Norway. 30pp.

Lotka AJ. 1925. Elements of Physical Biology. Baltimore: Williams and Wilkins Co.

398

McCormick SD, and Bjørnsson BT. 1994. Physiological and hormonal differences among 399 Atlantic salmon parr and smolts reared in the wild, and hatchery smolts. Aquaculture 400 $121: 235-244$.

401

Michalsen K, Ottersen G, and Nakken O. 1998. Growth of North-east Arctic cod (Gadus morhua 402 L.) in relation to ambient temperature. Ices Journal of Marine Science 55:863-877.

Ottersen G, Michalsen K, and Nakken O. 1998. Ambient temperature and distribution of north404 east Arctic cod. Ices Journal of Marine Science 55:67-85.

405 Pitcher TJ, and Hart PJB. 1982. Fisheries Ecology. London: Chapman and Hall.

406 Rønnestad I, Yufera M, Überschär B, Ribeiro L, Sæle Ø, and Boglione C. 2013. Feeding 407 behaviour and digestive physiology in larval fish: current knowledge and gaps and 408 bottlenecks in research. Reviews in Aquaculture 5:S59-S98.

409 Sæle O, and Pittman KA. 2010. Looking closer at the determining of a phenotype? Compare by 410 stages or size, not age. Journal of Applied Ichthyology 26:294-297.

411 Sagazio A, Piantedosi R, Alba M, Blaner WS, and Salvatori R. 2007. Vitamin A deficiency does 412 not influence longitudinal growth in mice. Nutrition 23:483-488.

413 Schaefer MB. 1957. Some Considerations of Population Dynamics and Economics in Relation to 414 the Management of the Commercial Marine Fisheries. Journal of the Fisheries Research 415 Board of Canada 14:669-681. 
416 Volterra V. 1926. Variazioni e fluttuazioni del numero d'individui in specie animali conviventi. 417 Mem R Accad Naz dei Lincei Ser VI 2. 


\section{Figure 1}

Growth in Zebrafish kept under constant conditions and fed to satiation through one generation

A. Growth in length by age (Mean $\pm S D, n=30$ fish; Gomez-Requeni et al., 2010, $n=30$, Kaushik et al., 2011, $n=10-18$ ). B. Calculated length increment by length for all data-points in Gomez-Requeni et al. (2010) with a second order polynomial fit $\left(y=-0.0027 x^{2}+0.078 x+0.25\right.$ $\left(R^{2}=0.994\right)$. C. Points past the exponential growth phase in Gomez-Requeni et al. (2010) fitted to a $2^{\text {nd }}$ order polynomial (blue line, $R^{2}=0.999$ ) and a linear (red line, $R^{2}=0.989$ ) equation and data from Kaushik et al (2011), fitted to a linear $\left(R^{2}=0.55\right)$ or an exponential $\left(R^{2}=0.60\right)$ equation (green; the lines of the models are overlapping). 

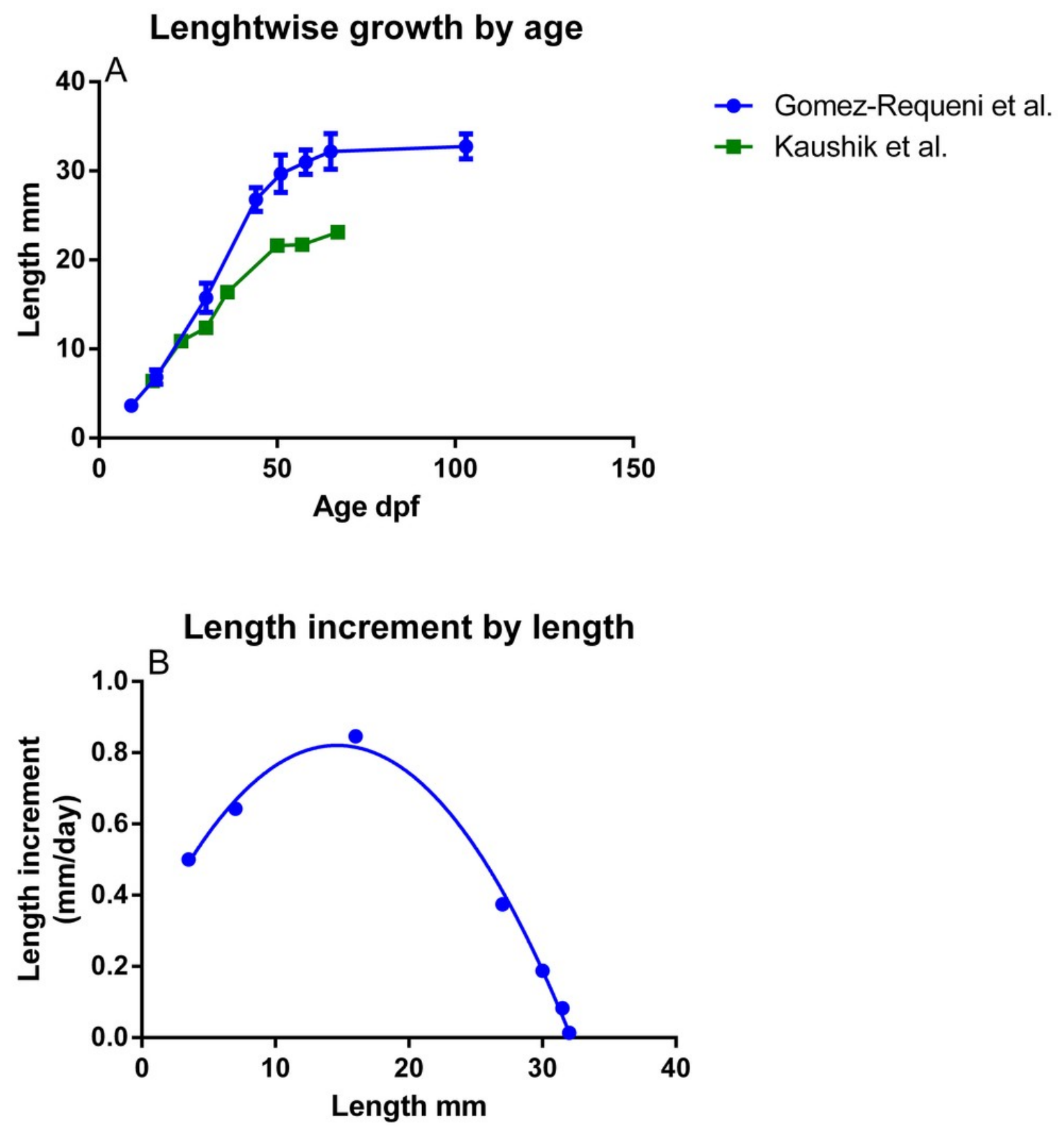

Length increment after the exponential phase

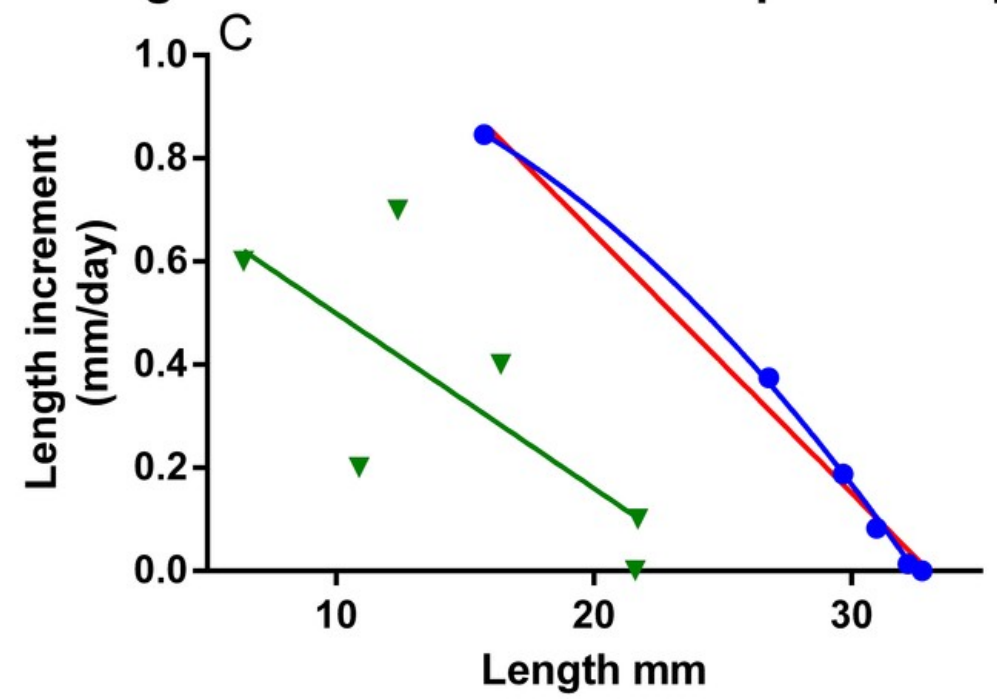

$\rightarrow$ Gomez-Requeni et al.

$\rightarrow$ Kaushik et al. 


\section{Figure 2}

Growth in the year-classes 1985-1995 of Norwegian spring spawning herring

A. Growth as length by age (Mean $\pm S D, n=11$ year classes). B. Average length increment by length in all year-classes from 1985 until 1995, fitted to a $2^{\text {nd }}$ order polynomial (blue line, $R^{2}=0.998$ ) and a linear (red line, $R^{2}=0.990$ ) equation. $C$. Length increment by length fitted to linear equations in the year-classes $1988\left(R^{2}=0.996\right)$ and $1989\left(R^{2}=0.996\right)$. D. Length increment by length in the year-class 1993, where the points for 3-9 year old fish were fitted to a linear equation $\left(R^{2}=0.996\right)$.
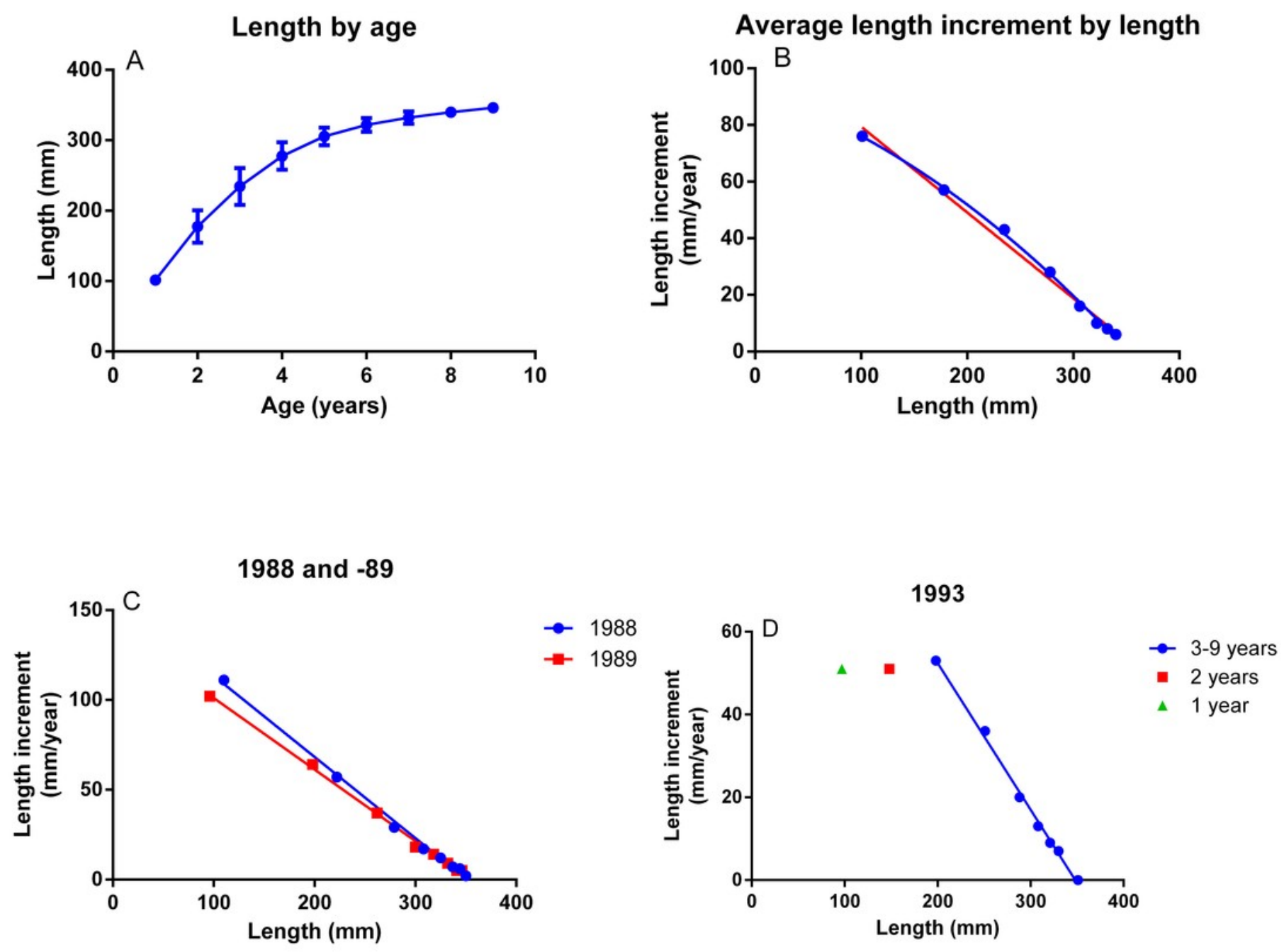


\section{Figure 3}

$k$ in herring of different ages in the year-classes 1985-1995.

$k$ was calculated from the slope of equation $1: d L=k \cdot(L \max -L s)$, where $d L$ is length increment and Ls is the measured length.

\section{k by year-class}

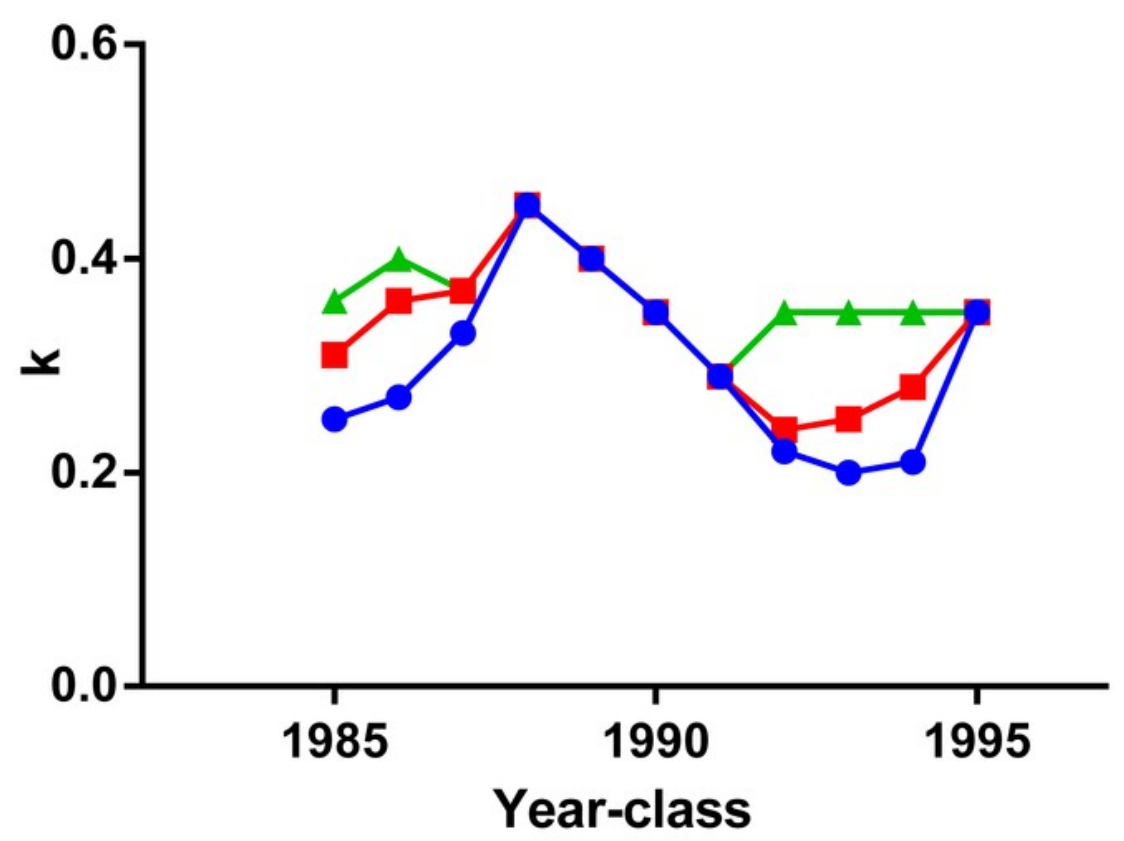

$\rightarrow \mathrm{k} 1$ year

$-\mathrm{k} 2$ years

$\leftarrow$ k 3-9 years

Year-class 


\section{Figure 4}

Growth in capelin from the Barents Sea

A. Growth as length by age (Mean $\pm S D, n=16$ year classes). B. Average length increment by length in all year-classes from 1986 until 2001, fitted to a $2^{\text {nd }}$ order polynomial (blue line, $R^{2}=0.998$ ) and a linear (red line, $R^{2}=0.977$ ) equation. 


\section{Length by age}

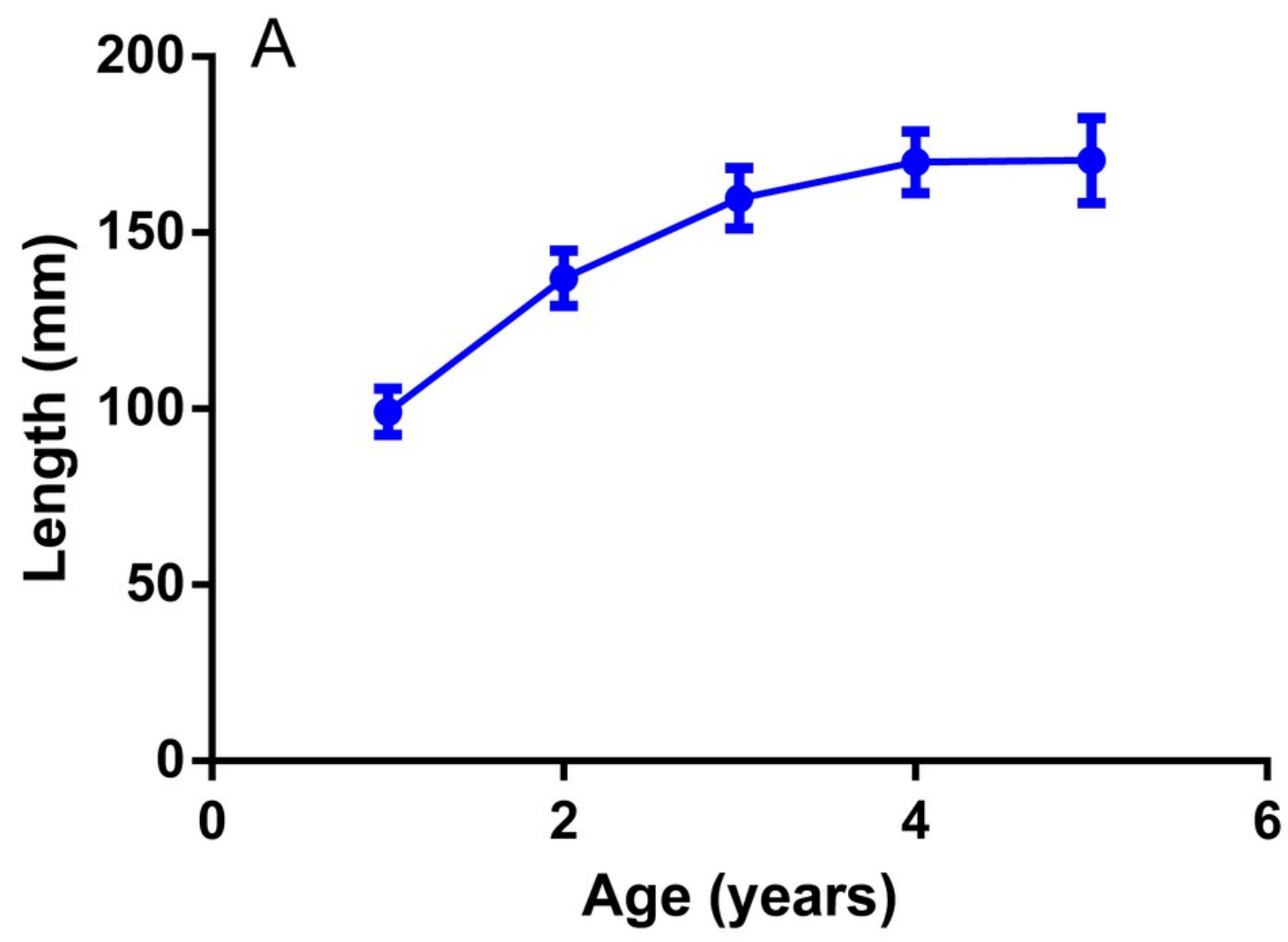

\section{Length increment by length}

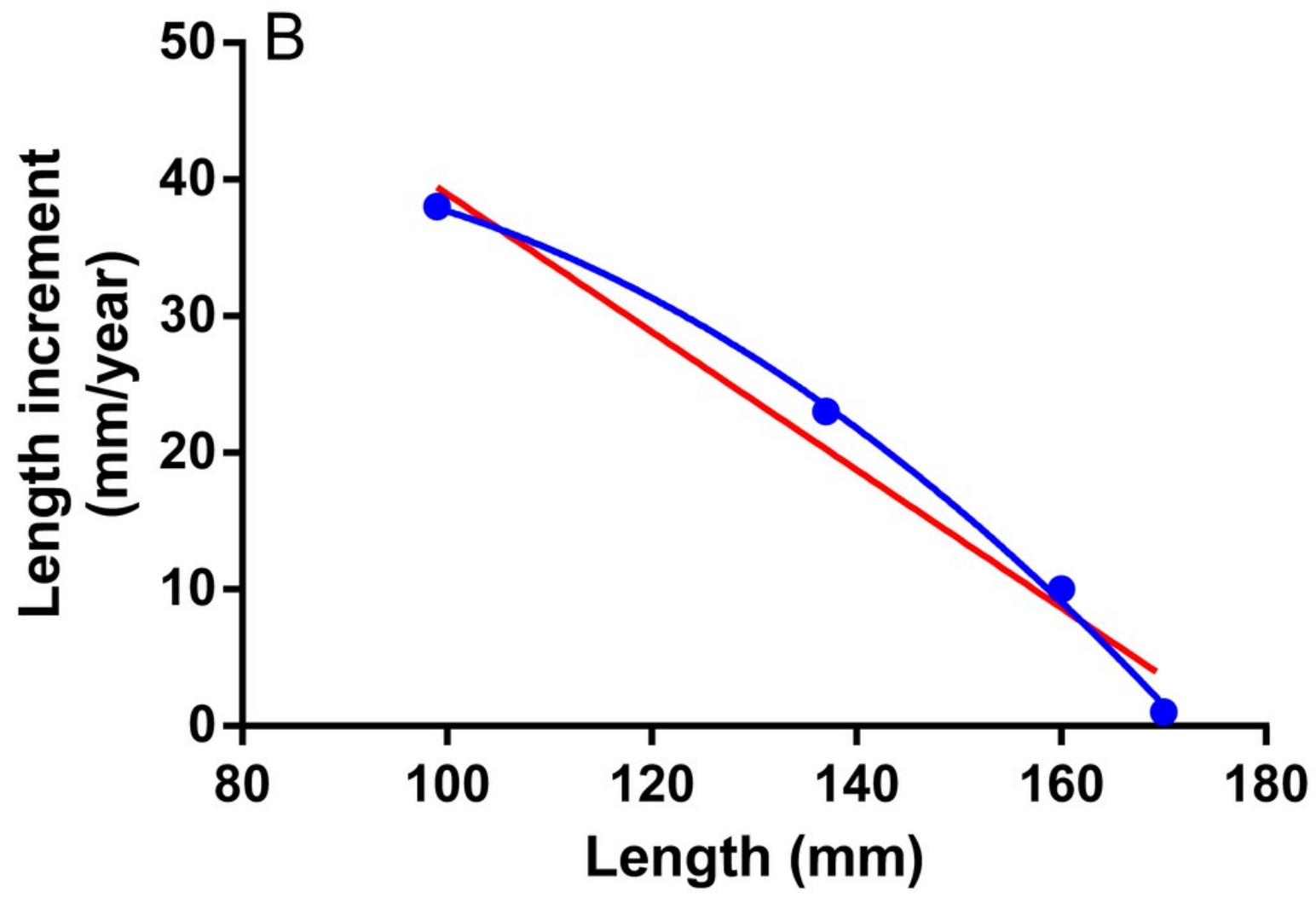




\section{Figure 5}

Growth in North Sea herring, blue whiting from the Norwegian Sea and Walleye Pollock from the Eastern Bering Sea.

A, C, E. Growth as length by age (Mean $\pm S D, n=11$ survey years for North Sea herring, $n=22$ year classes for blue whiting and $n=18$ year classes for Pollock). B, D, F. Average length increment by length in all year-classes listed above, fitted to a $2^{\text {nd }}$ order polynomial (blue line, $\mathrm{R}^{2}=0.977,0.980,0.988$, for herring, blue whiting and Pollock, respectively) and a linear (red line, $\left.R^{2}=0.973,0.888,0.948\right)$ equation. 
North Sea Herring

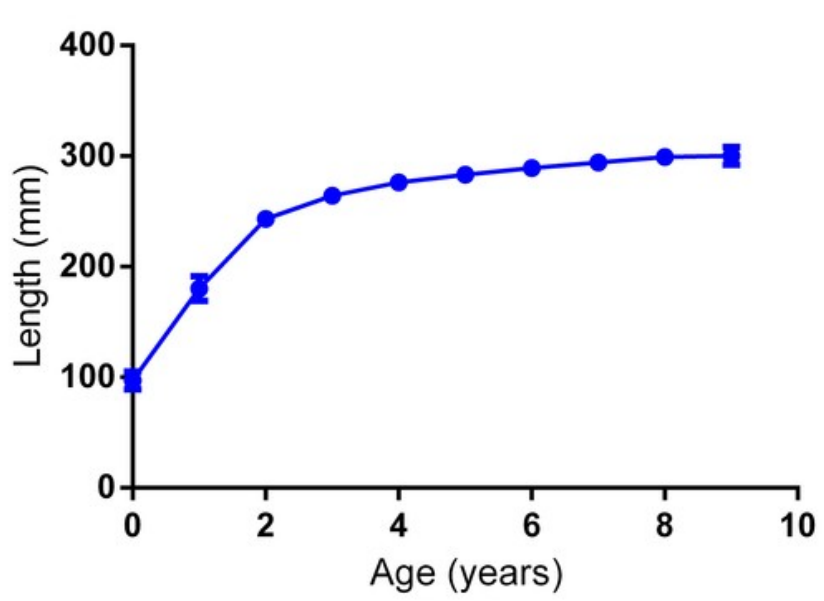

Blue whiting

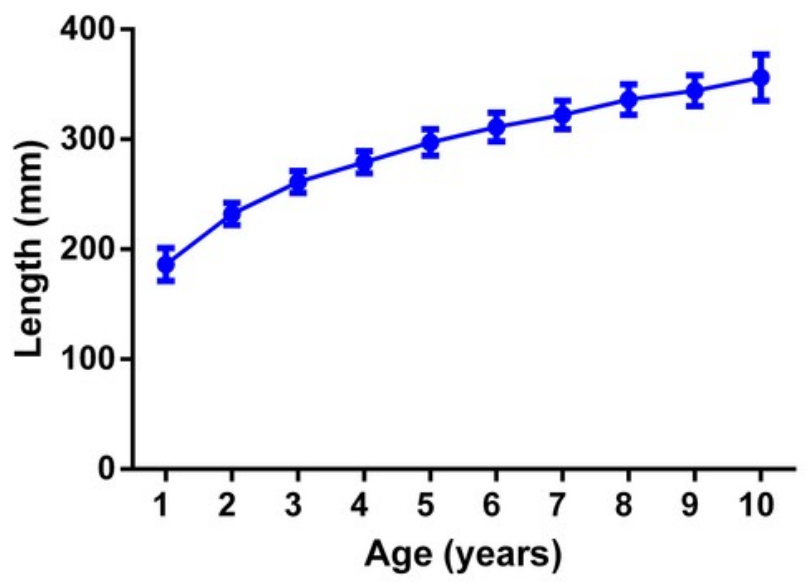

Pollock

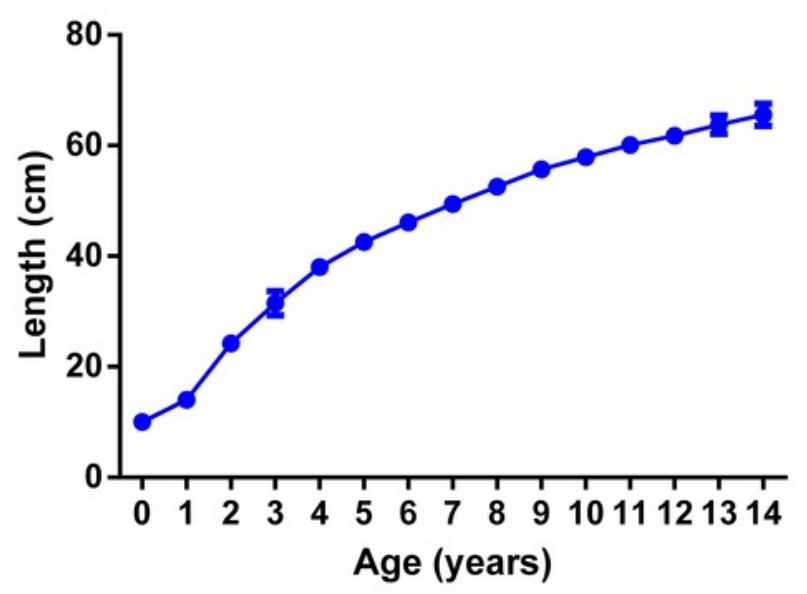

North Sea herring

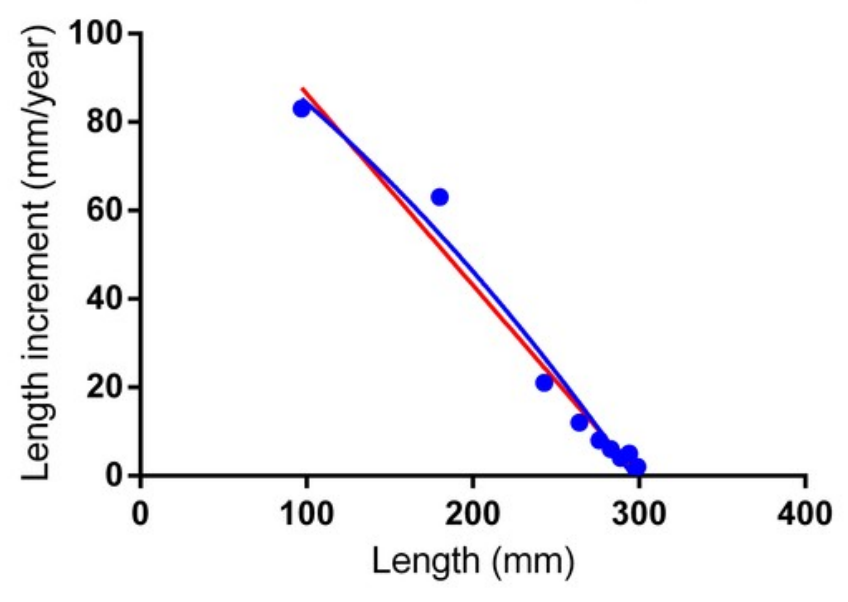

Blue whiting

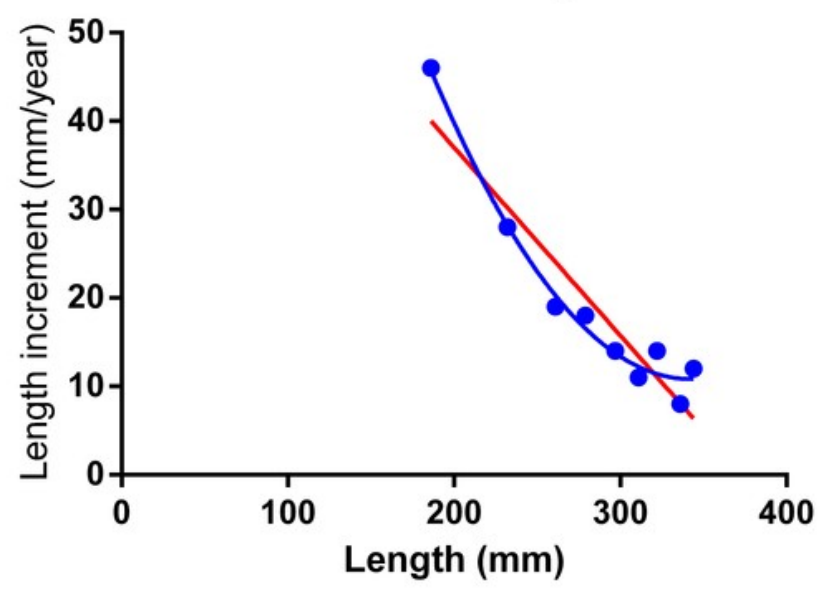

Pollock

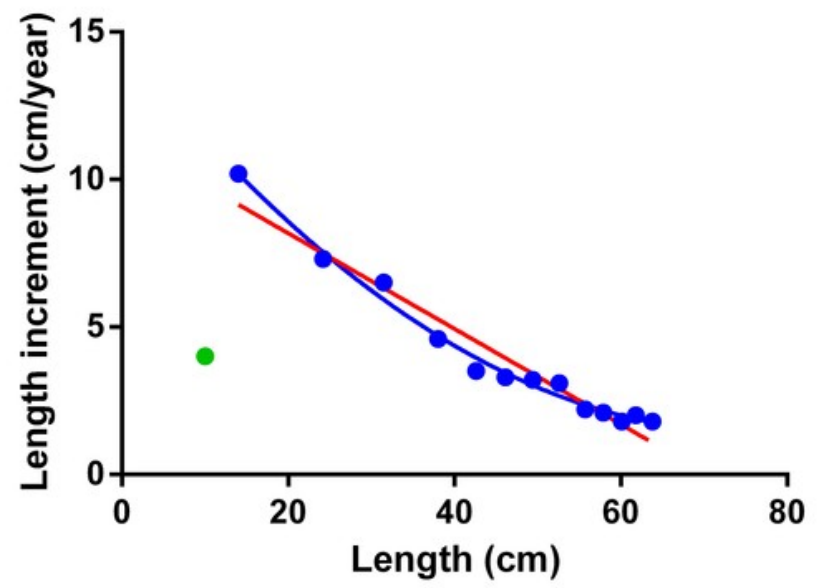




\section{Figure 6}

Growth in cod

A. Baretns Sea cod. Growth as length by age (Mean $\pm S D, n=11$ year classes). B Barents Sea cod. Average length increment by length in all year-classes from 1985 until 1995. C. North Sea cod. Growth as length by age (Mean $\pm S D, n=11$ year classes). D. North Sea cod. Average length increment by length in all year-classes from 1985 until 1995. The points for fish longer than $70 \mathrm{~cm}$ are fitted to an $2^{\text {nd }}$ order polynomial $\left(R^{2}=0.980\right)$ and a linear $\left(R^{2}=0.979\right)$ equation (both equations are represented by the red line). E. Farmed coastal cod held in net pens with seasonal variation in light and temperature but with constant feed supply, feed and feeding regime for one generation. Growth as length by age (Mean $\pm S D$, $\mathrm{n}=70$ fish). F. Farmed coastal cod. Average length increment by length fitted to an $2^{\text {nd }}$ order polynomial (blue, $R^{2}=0.801$ ) and a linear (red, $R^{2}=0.788$ ) equation. 
Length by age

Barents Sea

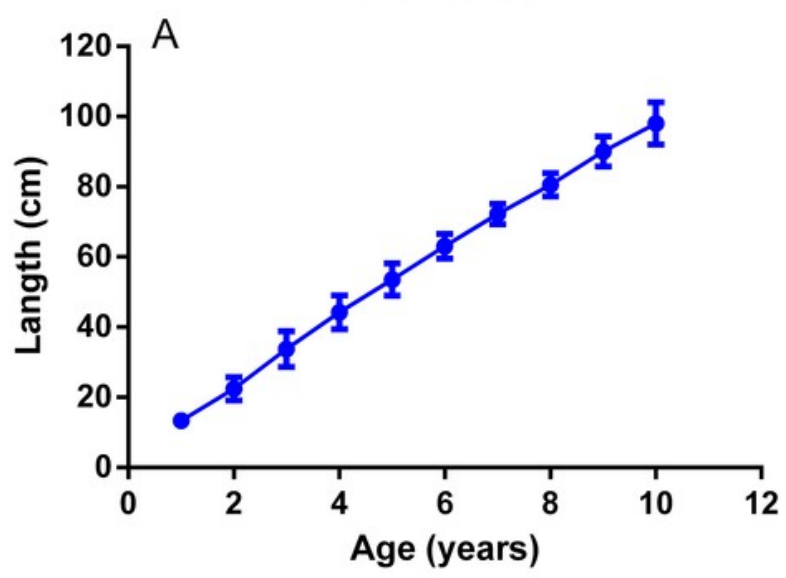

Length by age

North Sea cod

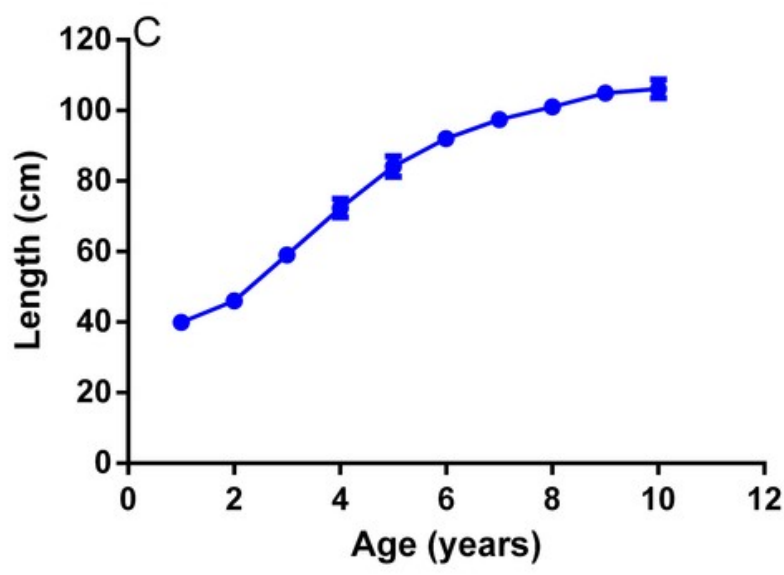

Length by age

Farmed cod

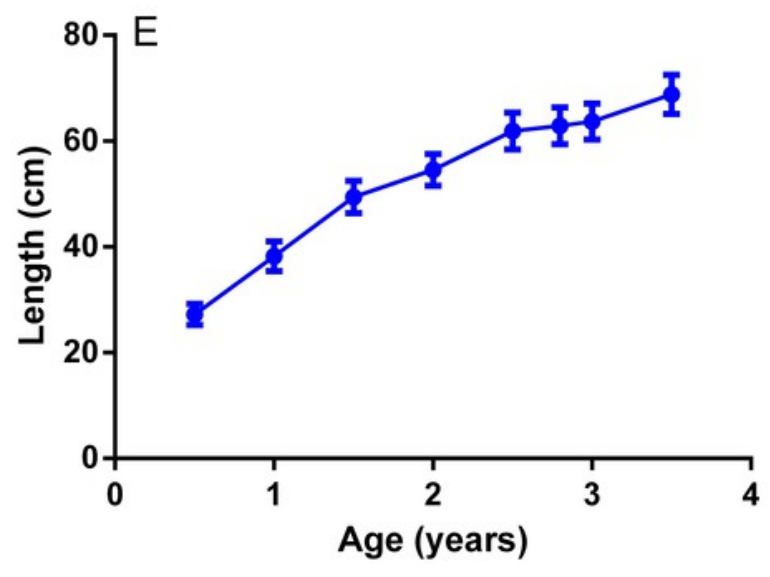

Length increment by length Barents Sea cod

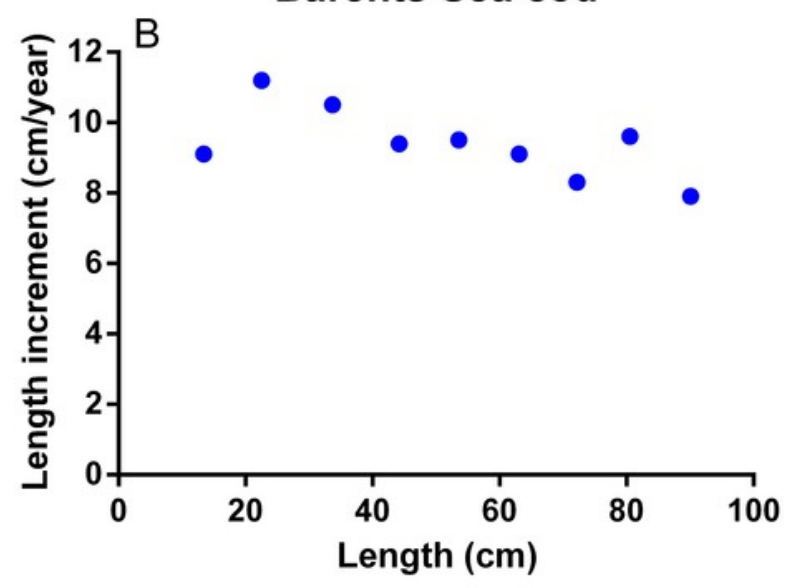

Length increment by length North Sea cod

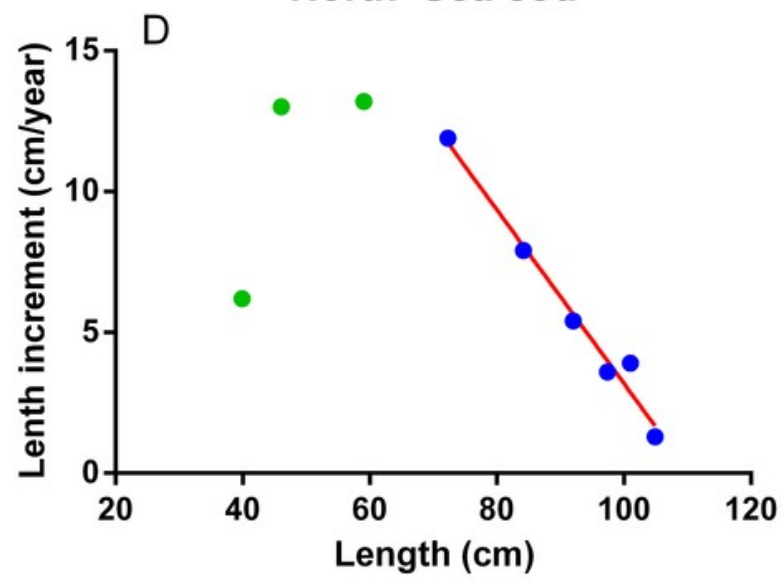

Length increment by lenght Farmed cod

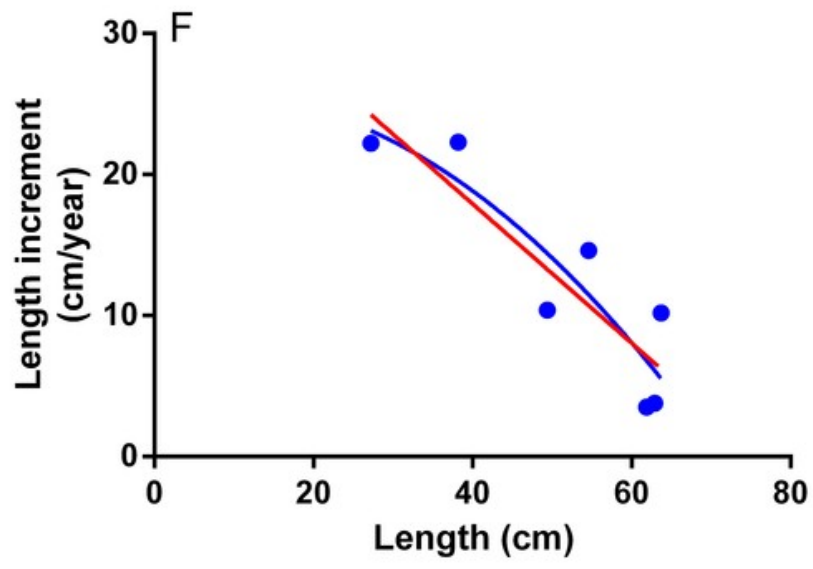

